\title{
FLORIAN PREISIG, Le rondeau 57 de Marot et les résonances culturelles d'un baiser qui «suce l'âme»
}

Filippo Fassina

\section{OpenEdition}

\section{Journals}

\section{Edizione digitale}

URL: https://journals.openedition.org/studifrancesi/43724

DOI: 10.4000/studifrancesi.43724

ISSN: 2421-5856

\section{Editore}

Rosenberg \& Sellier

\section{Edizione cartacea}

Data di pubblicazione: 1 juin 2021

Paginazione: 207

ISSN: 0039-2944

\section{Notizia bibliografica digitale}

Filippo Fassina, «FLoRIAN PREISIG, Le rondeau 57 de Marot et les résonances culturelles d'un baiser qui «suce l'âme»», Studi Francesi [Online], 193 (LXV | I) | 2021, online dal 01 juillet 2021, consultato il 15 octobre 2022. URL: http://journals.openedition.org/studifrancesi/43724 ; DOI: https://doi.org/10.4000/ studifrancesi.43724

Questo documento è stato generato automaticamente il 15 octobre 2022

\section{(c) $($ ) $(9)$}

Creative Commons - Attribuzione - Non commerciale - Non opere derivate 4.0 Internazionale - CC BY NC-ND 4.0

https://creativecommons.org/licenses/by-nc-nd/4.0/ 


\title{
FLORIAN PREISIG, Le rondeau 57 de Marot et les résonances culturelles d'un baiser qui «suce l'âme»
}

\author{
Filippo Fassina
}

\section{NOTIZIA}

FLORIAN PREISIG, Le rondeau 57 de Marot et les résonances culturelles d'un baiser qui «suce l'âme», "Bibliothèque d'Humanisme et Renaissance", LXXXI, 3 (2019), pp. 425-445.

1 Il motivo del bacio all'interno dei rondeaux pubblicati nella prima metà del xvi secolo è piuttosto raro. In particolare, nella produzione di Marot, il rondeau 57, che contiene l'immagine dell'anima del poeta risucchiata dalle labbra dell'amata, costituisce un unicum che merita un'attenzione particolare, soprattutto per quanto concerne le fonti. In primo luogo, risulta evidente una ripresa del topos classico del bacio, presente sia nello Pseudo-Platone, sia nei poeti latini (Catullo, Properzio). L'A. tuttavia prende in considerazione anche la versione neoplatonica del rapporto fra bacio e anima, resa celebre da Castiglione nel Cortegiano, opera ripresa spesso in Francia, ad esempio da Louise Labé e dai poeti della Pléiade. Altra possibile fonte, secondo l'A., sarebbe il componimento Proci et Puellae, inserito nei Colloques di Erasmo, componimento che ha come tematica fondamentale la fuga dell'anima dal corpo durante il bacio. Tuttavia, la filosofia neoplatonica risulta piuttosto estranea alla poetica di Marot: pertanto, l'A. ipotizza che il tema del bacio sia utilizzato più come un topos mutuato dalla poesia italiana del Quattrocento. Sembra infatti certo che Marot conoscesse bene uno strambotto di Serafino Aquilano (Incolpa, donna, amor) e uno di Olimpo di Sassoferrato ( $E$ poi con la mia bocca li donava), ma anche i poeti neolatini come Pontano e Marullo. Inoltre, viene identificata come un'altra possibile fonte diretta di Marot una composizione erotica intitolata Carmen ad Lydiam dello Pseudo-Gallo, dalla quale sarebbe stata ripresa l'immagine dell'anima risucchiata (animum sugere). Infine, 
l'ambiguità del bacio, legato sia alla spiritualità sia alla carnalità, potrebbe essere ripresa dal Cantico dei cantici, che era sicuramente ben conosciuto da Marot. In conclusione, nel rondeau 57 confluiscono numerose fonti, dai classici ai neolatini, dai neo-petrarchisti alla Bibbia, fonti che si sovrappongono rendendo il componimento così straordinariamente unico all'interno della produzione di Marot. 